\title{
Early Smoke Detection on Video Using Wavelet Energy
}

\author{
Muhammad Zulfiqar Shafar ${ }^{\# 1}$, Tjokorda A. Budi Wirayuda ${ }^{\# 2}$, Febryanti Sthevanie ${ }^{\# 3}$ \\ \# School of Computing, Telkom University \\ Jl. Telekomunikasi No.01 Terusan Buah Batu, Bandung, Jawa Barat, Indonesia \\ ${ }^{1}$ zulfiqarshafar@student.telkomuniversity.ac.id \\ ${ }^{2}$ cokagung@telkomuniversity.ac.id \\ ${ }^{3}$ sthevanie@telkomuniversity.ac.id
}

\begin{abstract}
Most of the smoke detection system these days still using sensors that have to receive specific particles before it could give a warning. But, this system takes some time to react and quite difficult to place in spacious room or the outdoor. To overcome this, there is some research that build smoke detection system using many kind video processing technique that could provide early warning. In this research, wavelet energy was used to detect smoke in the video. To determine candidate blocks in a frame that contain smoke, this research performed background subtraction and color analysis based on HSV color space. Then implementing spatial analysis and spatio-temporal analysis by using wavelet energy method and accumulative motion orientation to detect the smoke. This system using combination of dataset from previous research [1], downloaded from various sources and selfmade dataset. Based on testing process using those dataset, this system reaches $91.05 \%$ accuracy for block-level and $72.22 \%$ accuracy for frame-level.
\end{abstract}

Keywords: Accumulative motion orientation, smoke detection, spatial analysis, spatio-temporal analysis, video processing, wavelet energy

\begin{abstract}
Abstrak
Sebagian besar sistem deteksi asap saat ini masih menggunakan sensor yang akan menangkap partikel tertentu sebelum dapat memberi peringatan. Namun, sistem ini membutuhkan waktu yang cukup lama untuk bereaksi dan sulit jika dipasang di ruang luas ataupun terbuka. Untuk mengatasi kekurangan ini, banyak dilakukan penelitian yang membangun sistem deteksi asap menggunakan berbagai teknik video processing yang dapat lebih menjamin untuk memberi peringatan dini. Dalam penelitian ini, digunakan metode wavelet energy untuk mendeteksi asap pada video. Untuk menentukan kandidat blok pada frame yang mengandung asap, dilakukan background subtraction dan analisa warna berdasarkan model HSV. Lalu digunakan metode wavelet energy pada spatial analysis dan spatio-temporal analysis serta metode accumulative motion orientation untuk mendeteksi asap. Dataset yang digunakan pada sistem yang dibangun merupakan kombinasi dari dataset penelitian sebelumnya [1], unduhan dari berbagai sumber serta dataet yang dibangun secara mandiri. Berdasarkan pengujian yang dilakukan menggunakan dataset tersebut, sistem ini menghasilkan tingkat akurasi sebesar pada level blok sebesar $91.05 \%$ dan tingkat akurasi pada level frame sebesar $72.22 \%$.
\end{abstract}

Kata Kunci: Accumulative motion orientation, deteksi asap, spatial analysis, spatio-temporal analysis, video processing, wavelet energy 


\section{A. INTRODUCTION}

MOKE detectors are widely used nowadays in various places. It is usually a sensor-based that need to capture certain particles before giving a warning of smoke presence. However, such kind of detectors need some time and need to be placed in a certain position so that smoke can reach the sensor.

Several studies have been developed to replace smoke sensors, one of them is by using video. Video-based smoke detection system can be promising, given the smoke arises before a fire. The source of smoke may be out of range of the video or hindered by other objects so it cannot be captured by video, hence the smoke detection system capable to warn earlier than the fire detection system if dangerous things happen such as wildfire. Furthermore, video can also be used to cover large or open areas and this system only need to be installed on video surveillance system that is widely used.

In developing smoke detection systems using video, there are some challenges such as variations of the shape, motion, and texture of the smoke that can be affected by background and luminance levels in the video [2]. In a previous study, Gomez-Rodriguez et al. [3] applying wavelet and optical flow methods to detect smoke presence. Meanwhile, Toreyin et al. in [4] introducing the wavelet coefficient method by carrying out temporal and spatial wavelet analysis. Research by Avgerinakis et al. [2] implemented a smoke detection algorithm using temporal HOGHOF descriptors and energy color statistics. And in a recent study by Dimitropoulos et al. [1] [5] uses spatio-temporal wavelet analysis, HOGHOF descriptors, and linear dynamical system to detect smoke with a high accuracy. This mentioned studies, use wavelet energy method because smoke generally will smoothen the edges in an image if it is not that thick [4] [6]. This feature of smoke then used as an indicator of its presence in video [4] [6]. In the wavelet domain, extreme points represented by edges in an image [4] [6]. If the smoke cover the edges, it will make the extreme point of the edges being reduced even if it does not reach zero. In fact, the edge remains in its position but will lose some of their wavelet energy because it is covered by smoke which is a semi-transparent object [4] [6].

In this research, spatial and spatio-temporal smoke analysis using wavelet energy method are implemented to obtain energy of smoke, then accumulative motion orientation method are used to determine smoke motion orientation. Both of these process are combined to distinguish smoke from non-smoke or smoke-colored objects and then can be used to determine the smoke presence in a video.

\section{LITERATURE REVIEW}

\section{A. HSV Color Model}

Every color in the real world are represented to computer by color space [7]. HSV color model uses three components to represent the colors, Hue (H), Saturation (S), and Value (V). HSV color model was developed to resemble how human perceive colors. Beside that, the HSV color wheel is more often to be used for generating high-quality graphics because it is easier to choose the color required [8].

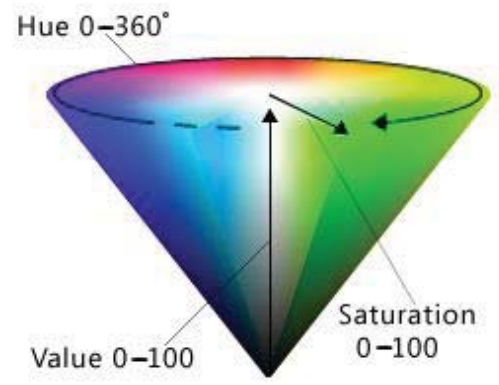

Figure 1. HSV Color Space Illustration [9] 
Hue represents the true color that has a range of values between 0 degrees to 360 degrees or can be recalculated to 0 to 100 . Hue degrees will represent a color, starting from 0 degrees is red, starting from 60 degrees is yellow, starting from 120 degrees is green, starting from 180 degrees is cyan, starting from 240 Degrees are blue, and starting from 300 is magenta [8]. Saturation shows the level of clarity of a color that has a range of values from 0 to 100 or can be recalculated to 0 to 1 . A color will look more faded when closer to 0 and will look more saturated when close to 100 . Value indicates the level of brightness of color that has a range of values from 0 to 100 or can be recalculated to 0 to 1 . The value 0 will represent the black color and will become brighter until white at 100 [9].

\section{B. Frame Differencing}

Frame Differencing is one of the background subtraction technique that aims to separate the background from foreground. Furthermore, it is also can be used to detect moving objects. Simplicity of this process that might result in short processing time is the advantage of this method [10]. The following figure shows an image or frame in a video with smoke along with the marker of the image showing the background marked in black and the foreground marked in white.

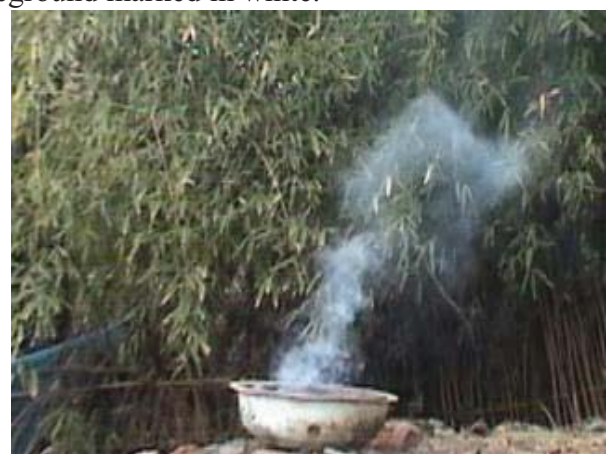

Figure 2. Image with moving object

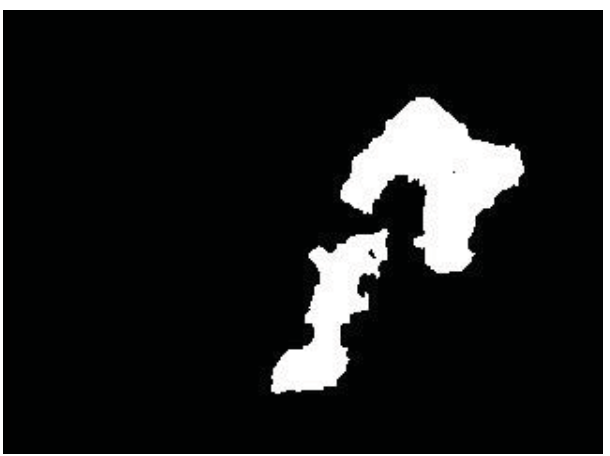

Figure 3. Marker of the moving region

Frame differencing techniques is implemented by differencing two frames, frame at time $t$ - $\Delta t$ and frame at time $t$. Frame differencing formula is defined as [11].

Where:

$$
b_{t}(x, y)= \begin{cases}1 & ,\left|I_{t}(x, y)-I_{t-\Delta t}(x, y)\right|>\text { Threshold } \\ 0 & , \text { else }\end{cases}
$$

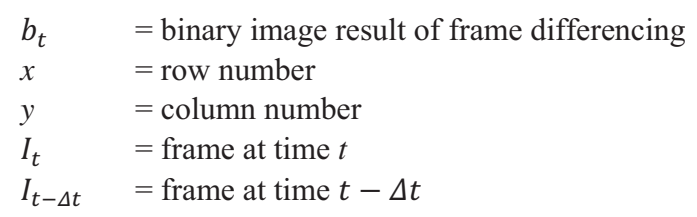

The difference value in each pixel of both frames will be measured. If the difference is greater than the threshold, it will be marked by 1 , whereas if the difference is smaller than the threshold will marked by 0 in the binary image. This binary image will be used as a marker to show the foreground and background of the current frame.

\section{Spatial Wavelet Analysis}

Wavelet is a wave that oscillate from zero, increases, then decreases back to zero [12]. Wavelet value are used in transformation functions called wavelet transforms. In the field of image processing, wavelet transform is more widely used than Fourier transforms. This is because the wavelet transform is capable of providing the time when it is transformed into the frequency domain [12]. In its application to the smoke detection system, 
the wavelet transform is utilized to distinguish noise or edge signals and it is the one of the main reason wavelet are used in this system.

An image containing smoke generally has a lower spatial value than an image containing a smoke-colored object with a lot of textures or shades, but it will have a higher spatial value than an image containing solid smoke-colored object. Therefore, spatial values are used to extract the characteristics of a smoke. To obtain the spatial value, the 2-D wavelet analysis algorithm is applied and implemented for white to gray image region, the spatial wavelet energy is determined by calculating the change of frequency of high-low, low-high, and high-high with the following formula [1]:

Where:

$$
E(i, j)=H L(i, j)^{2}+L H(i, j)^{2}+H H(i, j)^{2}
$$

$$
\begin{array}{ll}
\mathrm{HL} & =\text { high-low sub-bands of wavelet decomposition } \\
\mathrm{LH} & =\text { low-high sub-bands of wavelet decomposition } \\
\mathrm{HH} & =\text { high-high sub-bands of wavelet decomposition } \\
i & =\text { row number } \\
j & =\text { column number }
\end{array}
$$

The spatial-wavelet energy of each candidate block is estimated as the average of the energy of each pixel in the block [1].

Where:

$$
E_{\text {block }}=\frac{1}{N^{2}} \sum_{i, j} E(i, j)
$$

$N \quad=$ number of row or column in a block
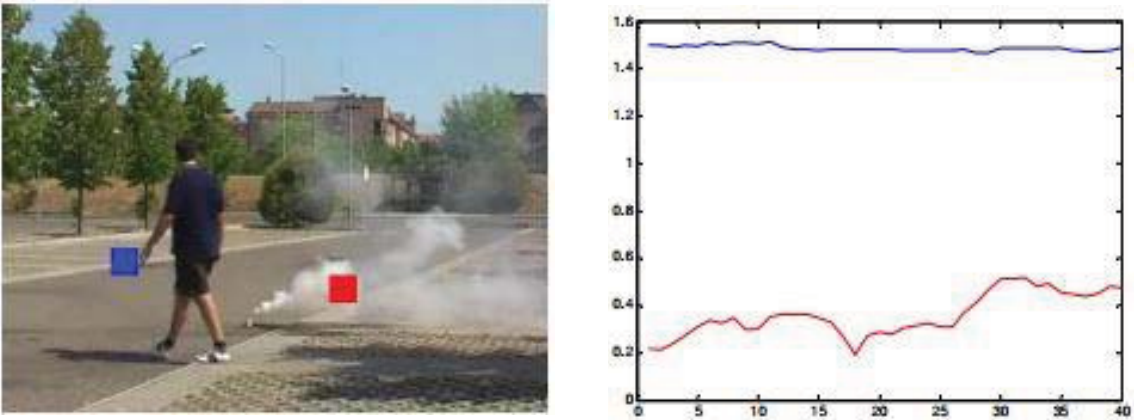

Figure 4. (Left) Frame and (right) graph of energy of smoke (red block and line) and non-smoke object (blue block and line) [1]

\section{Spatio-temporal Wavelet Analysis}

The shape of smoke changes irregularly due to the airflow [1]. Smoke generally have a higher spatial variations compared to smoke-colored objects over a period of time [1] [13]. This process aims to measure spatio-temporal variations in the candidate block in a sequence of frames that contrast to the previous process which only counting spatial energy in a single frame [1]. 


\section{E. Accumulative Motion Orientation}

Accumulative Motion Orientation is a method to estimate motion orientation of smoke. There is 8-directions which are $0,45,90,135,180,225,270$, and 315 degrees, that represent the motion orientation of a block. These directions are coded as $1,2,3,4,5,6,7$, and 8 , respectively [11].

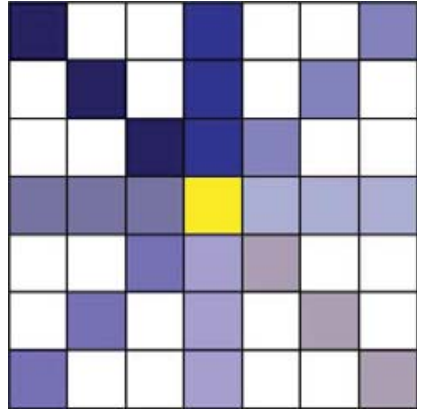

Figure 5. Searching scheme [11]

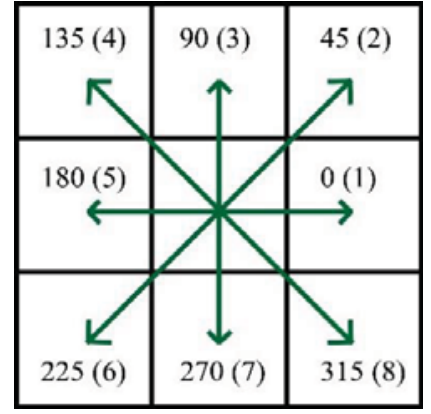

Figure 6. Smoke direction [11]

Each directions are calculated to estimate the motion orientation of a block. Based on previous research [11], three pixel displacements are used as the searching scheme, as shown in Figure 5. To estimate the motion orientation of a block, the difference of the grayscale block values are calculated in the current frame and the previous frame using error function follows [11]:

Where:

$$
E(i, j, \theta, d i s)=\left|\sum_{x, y \in b(i, j)} f(x, y, t)-\sum_{x, y \in b_{\prime}(i, j)} f(x, y, t-\Delta t)\right|
$$

$$
\begin{array}{ll}
\theta & =\text { direction coded as } 1,2,3,4,5,6,7, \text { and } 8 \\
\text { dis } & =\text { displacement defined as } 1,2, \text { and } 3 \\
b(i, j) & =i \text { th row and } j \text { th column of block in frame } t \\
b^{\prime}(i, j) & =i \text { th row and } j \text { th column of block in frame } t-\Delta t \\
f(x, y, t) & =x \text { th row and } y \text { th column of frame } t \\
f(x, y, t-\Delta t) & =x \text { th row and } y \text { th column of frame } t-\Delta t \\
\Delta t & =\text { time difference }
\end{array}
$$

For each direction, there will be three error values based on the displacement. The minimum error value will be defined as the error of the direction [11].

$$
E(i, j, \theta)=\min _{d i s} E(i, j, \theta, d i s)
$$

And the minimum error value of this direction is supposedly to be the motion orientation of the block, therefore the direction will be [11].

$$
\theta=\underset{\theta}{\operatorname{Arg} \min } E(i, j, d i s)
$$

But based on [11], the motion orientation of a block is the contrary of the real motion direction, therefore the direction code is modified by [11].

$$
\theta=\left\{\begin{array}{cl}
8 & \text {, if } \bmod (\theta+4,8)=0 \\
\bmod (\theta+4,8) & \text {, else }
\end{array}\right.
$$


And if a block have no motion then the motion orientation will be coded as 0 . To improve the accuracy of the estimated orientation, then the motion orientation of a block are accumulated over time $t$. The direction with maximal entry is considered as the motion orientation of the block.

\section{RESEARCH METHOD}

In general, the process in the video smoke detection system of this research is shown in the diagram below.

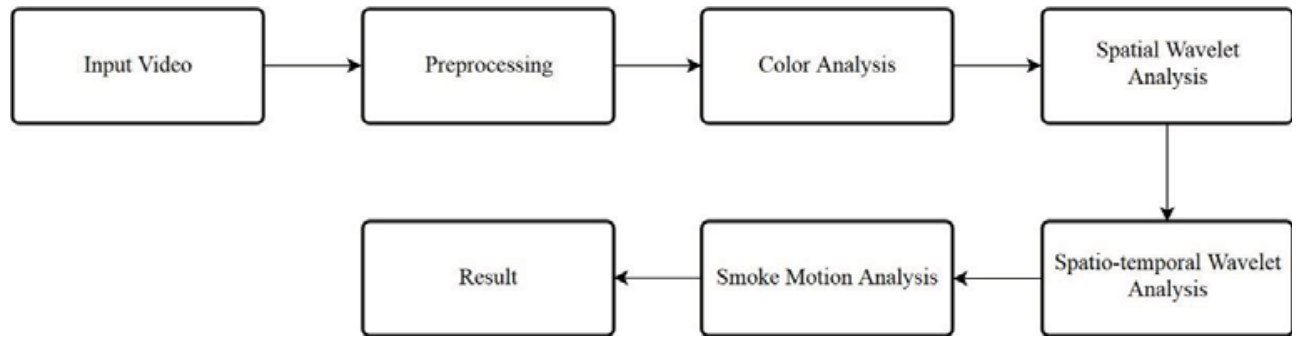

Figure 7. System Overview

The diagram above is the general overview of the smoke detection system through five phases, preprocessing, color analysis, spatial analysis, spatio-temporal analysis, and smoke motion analysis. The following is the detailed explanation of these processes.

\section{A. Video Preprocessing}

Before performing the smoke feature extraction on a video, each video will be processed in the preprocessing phase. Here is the preprocessing flowchart of this process.

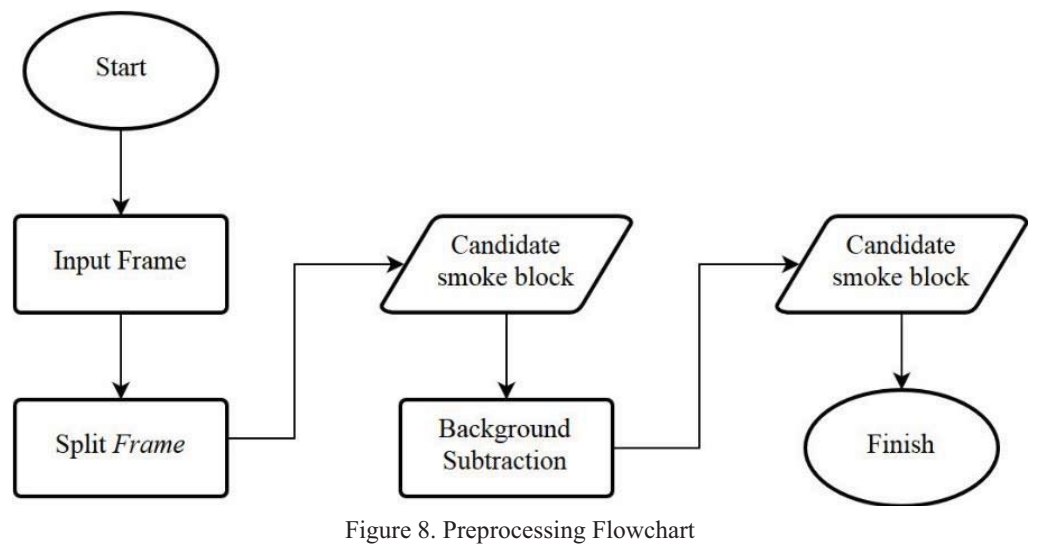

Preprocessing aims to reduce the computational cost of the system in processing video when performing feature extraction. The preprocessing phase consists of two processes, split frame and background subtraction. The processed frame will be cut into blocks of $16 \times 16$ pixels. The purpose of this process is to reduce the region of interest and reduce computational cost.

In background subtraction, frame differencing technique is used to compare two blocks, the block in the current frame and the block in the previous frame. The difference of both frames are calculated using equation (1). If the difference value of a pixel is greater than the threshold, it will be defined as a moving pixel and if smaller then it will be defined as a stationary pixel. The result of the frame differencing is a binary block. After that, the current blocks will be processed again through morphological operations which is erosion and dilation 
to reduce noise pixels. A block will be considered as a moving block if there is at least one moving pixel in the block. And then this moving blocks will become the input of the feature extraction processes.

\section{B. Color Analysis}

The next phase is the color analysis. From the previous process, the moving blocks has been obtained that become input for this process. At this process, the block containing smoke color will be separated from the block that have no smoke color.

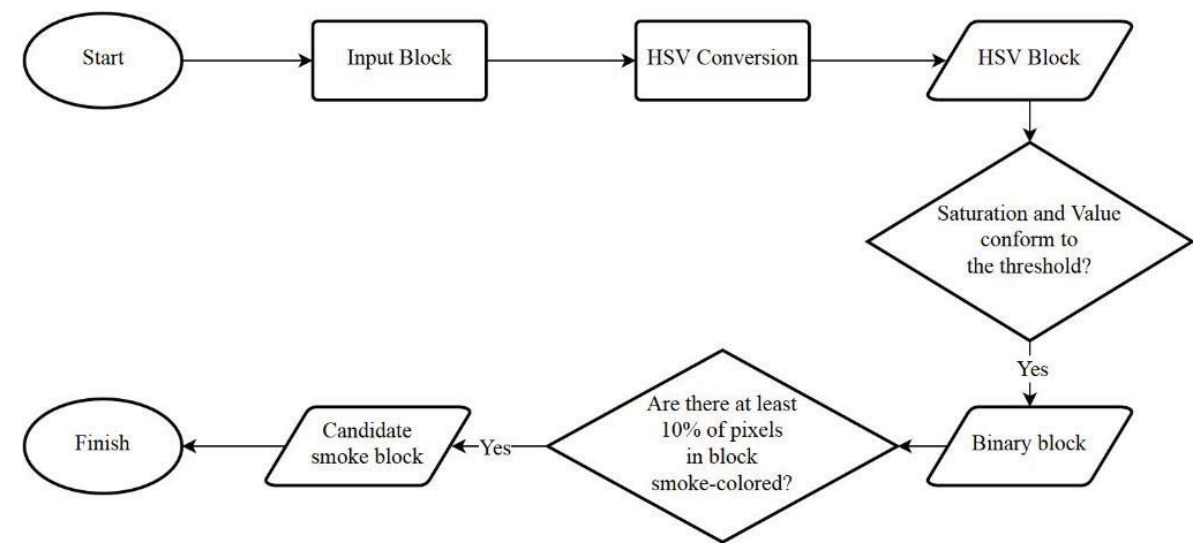

Figure 9. Color Analysis Flowchart

Block input of the previous process are using RGB color model, while in this process required block input in HSV color model, therefore the block need to be converted into HSV using the following equation [1]:

$$
\begin{gathered}
V=\max (R, G, B) \\
S=\left\{\begin{array}{cl}
\frac{V-\min (R, G, B)}{V} & , \text { if } V \neq 0 \\
0 & \text {, else }
\end{array}\right.
\end{gathered}
$$

After the conversion process, the value of Saturation and Value of each pixel in the block is examined. A pixel will be considered as smoke if:

$$
S<0.37 \text { and } V>0.64
$$

Where the values of the thresholds for Saturation and Value were experimentally determined using number of training videos. Then each pixels in the block that considered as smoke are summed up. In the previous studies [1] [5], if at least 10\% of pixels in the moving block are smoke-colored, then the block will be considered as candidate smoke block. 


\section{Spatial Wavelet Analysis}

In this phase, wavelet energy of each block is determined by calculating the high-low, low-high, and highhigh sub-bands from first level wavelet decomposition. Input from this process is the blocks that have been converted to grayscale after color analysis.

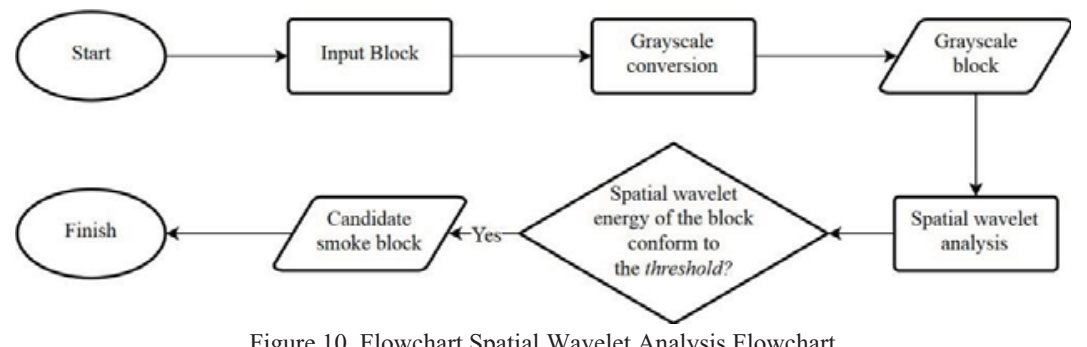

Figure 10. Flowchart Spatial Wavelet Analysis Flowchart

First level of wavelet decomposition have low-to-low (LL), high-to-low (HL), low-to-high (LH) and high-to-high $(\mathrm{HH})$ sub-bands. However, only the energy from high frequency are used in this system, which is calculated using formula (2). The energy of each pixel is then accumulated using equation (3) to obtain the spatial wavelet energy of the block. This energy then used to distinguish if a block is a smoke candidate block or a non-smoke candidate block.

\section{Spatio-temporal Wavelet Analysis}

At this phase, spatio-temporal wavelet energy wavelet the smoke candidate blocks are determined. Input of this process is blocks with grayscale value that have been processed by spatial wavelet analysis.

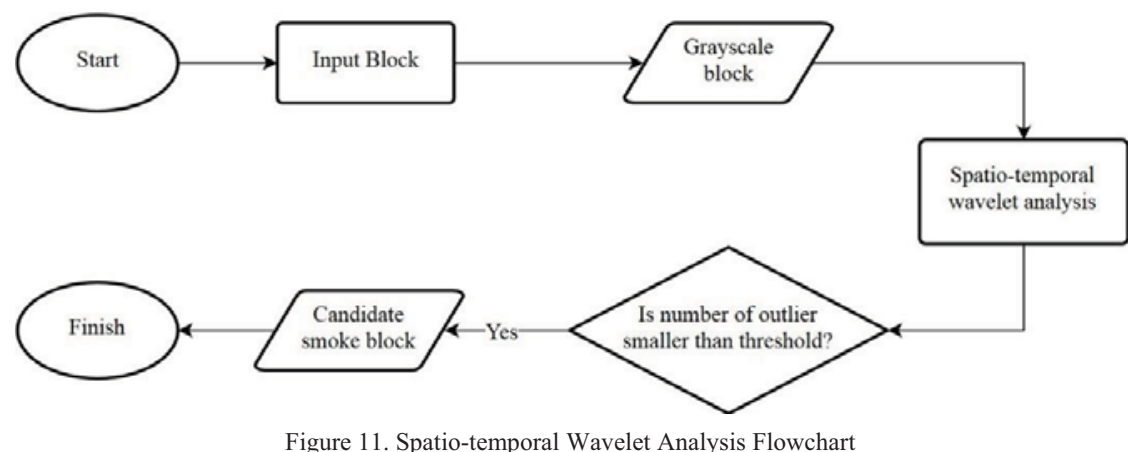

Over a period of time, the spatial energy of the current block will be determined. Each of this value then mapped to count the number of values that classified as the outlier. A block with a non-smoke object generally will have more outlier than a smoke block. Therefore, a block will be defined as a candidate smoke block if:

$$
\text { Number of outlier }>6
$$

Where this threshold was determined using number of training videos. The result of this process is the smoke blocks that have been selected based on the spatio-temporal energy it has. 


\section{E. Smoke Motion Analysis}

Beside analyzing the spatio-temporal energy, smoke motion orientation will be analyzed using accumulative motion orientation. Spatio-temporal wavelet analysis results will be used as input for this process.

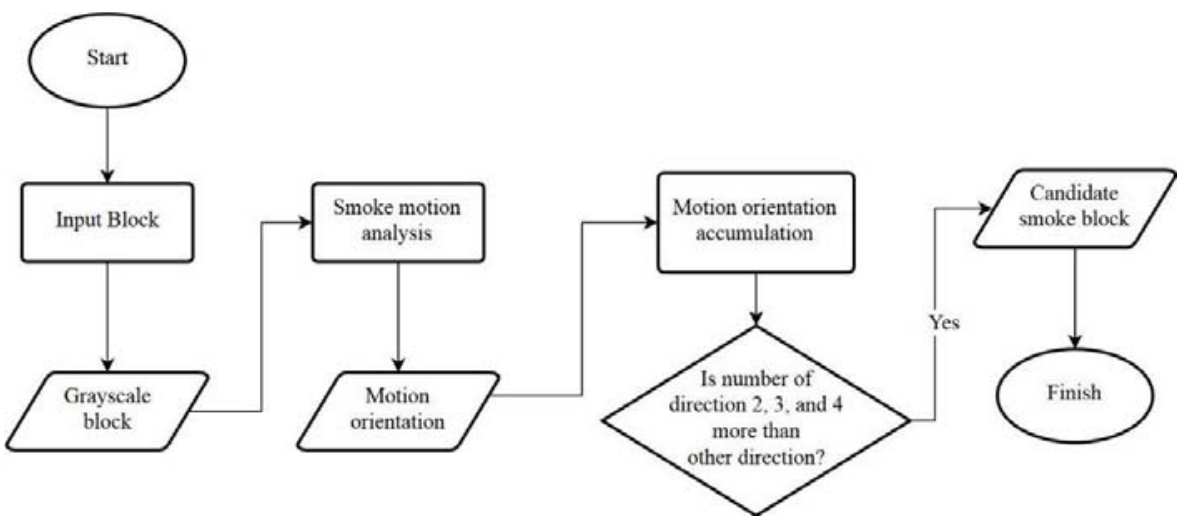

Figure 12. Smoke Motion Analysis Flowchart

Accumulative motion orientation aims to determine the motion direction of smoke block. The grayscale value of the current block will be compared with the search block using equation (4). By using equations (5) and (6), the motion direction will be analyzed. And then using equation (7) the real motion direction will be determined. Based on [11] [14], if the direction of the block is 2,3 , or 4 , then the block will be considered as candidate smoke block.

After that, each block will be accumulated for each motion direction over time $t$ (in this research is 100 frames). Since a smoke block will generally have a direction of 2,3 , or 4 , then the number of these directions will be summed up and then compared with the number of other direction. If within the period of time, the block have a number of directions 2, 3, and 4 more than the number of the other direction, then the block will be considered as a smoke block.

\section{RESULTS AND DisCUSSION}

In this research, a series of testing are carried out to measure the accuracy of the system. Here are the parameters configurations used.

TABLE I

PARAMETER CONFIGURATION

\begin{tabular}{|c|l|c|}
\hline No. & \multicolumn{1}{|c|}{ Parameter Name } & Parameter Value \\
\hline 1 & Frame differencing threshold & 11 \\
\hline 2 & Saturation threshold & 0.37 \\
\hline 3 & Value threshold & 0.64 \\
\hline 4 & Spatial wavelet energy range & $0.2-110$ \\
\hline 5 & Spatio-temporal wavelet energy outlier threshold & 6 \\
\hline 6 & Smoke motion number of frames & 110 \\
\hline
\end{tabular}

System testing consisted of block-level testing and frame-level testing. Block-level testing is performed to measure system accuracy based on the number of smoke blocks correctly detected by the system of all blocks in the testing video. Meanwhile, frame-level testing is performed to measure system accuracy based on the number of smoke frames correctly detected by the system of all frames in the testing video. The result of this testing phase using the parameter configuration above is. 
TABLE II

BLOCK-LEVEL TESTING RESUlT

\begin{tabular}{|c|l|c|c|c|c|c|c|}
\hline $\begin{array}{c}\text { Video } \\
\text { Type }\end{array}$ & Video Name & $\begin{array}{c}\text { Number } \\
\text { of Blocks }\end{array}$ & $\begin{array}{c}\text { True } \\
\text { Positive }\end{array}$ & $\begin{array}{c}\text { True } \\
\text { Negative }\end{array}$ & $\begin{array}{c}\text { False } \\
\text { Positive }\end{array}$ & $\begin{array}{c}\text { False } \\
\text { Negative }\end{array}$ & Accuracy \\
\hline \multirow{3}{*}{ Smoke } & visor08 & 3000 & 490 & 2141 & 10 & 359 & $87.70 \%$ \\
\cline { 2 - 7 } & visor10 & 1200 & 7 & 1115 & 24 & 54 & $93.50 \%$ \\
\cline { 2 - 8 } & sBtFence2 & 3600 & 190 & 2920 & 293 & 197 & $86.39 \%$ \\
\hline Non-smoke & Basketball_yard & 3000 & 0 & 2970 & 30 & 0 & $99 \%$ \\
\hline \multicolumn{2}{|c|}{ Total } & 10800 & 687 & 9146 & 357 & 610 & $91.05 \%$ \\
\hline
\end{tabular}

TABLE III

FRAME-LEVEL TESTING RESUlT

\begin{tabular}{|c|c|c|c|c|c|c|c|}
\hline $\begin{array}{l}\text { Video } \\
\text { Type }\end{array}$ & Video Name & $\begin{array}{l}\text { Number } \\
\text { of Frames }\end{array}$ & $\begin{array}{c}\text { True } \\
\text { Positive }\end{array}$ & $\begin{array}{c}\text { True } \\
\text { Negative }\end{array}$ & $\begin{array}{c}\text { False } \\
\text { Positive }\end{array}$ & $\begin{array}{c}\text { False } \\
\text { Negative }\end{array}$ & Accuracy \\
\hline \multirow{3}{*}{ Smoke } & visor08 & 300 & 300 & 0 & 0 & 0 & $100 \%$ \\
\hline & visor10 & 120 & 120 & 0 & 0 & 0 & $100 \%$ \\
\hline & sBtFence2 & 360 & 360 & 0 & 0 & 0 & $100 \%$ \\
\hline Non-smoke & Basketball_yard & 300 & 0 & 30 & 270 & 0 & $10 \%$ \\
\hline \multicolumn{2}{|c|}{ Total } & 1080 & 780 & 0 & 300 & 0 & $72.22 \%$ \\
\hline
\end{tabular}

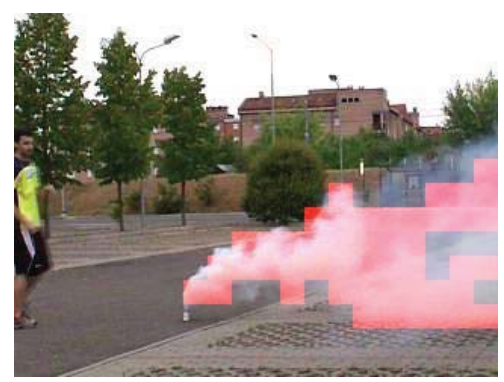

Figure 13. Frame Sample of Testing Result

From block-level testing results in Table II, it can be seen that the accuracy of the system at the block-level testing is $91.05 \%$ with the highest accuracy on the smoke video is $93.50 \%$ and the accuracy on the non-smoke video is $99 \%$.

The results of the testing show there are still many blocks of smoke that is not detected (false negative). This is mostly due to the smoke motion analysis process, the method is still imprecise because a smoke block is often considered static. In this block process, if the difference of grayscale value in the same position with the current block is the minimum error value, then the block will be considered static.

In the testing phase, the smoke blocks are often considered static when processing block at the center of the smoke. If a block is at the center of the smoke, the smoke motion usually cannot be detected because the block entirely covered by smoke color. When measuring the difference of grayscale values for blocks at the center of the smoke, it will usually have very small error values in the same position and most likely to be the minimum error value compared to the neighbor blocks. This is what happens to the smoke blocks that are incorrectly detected as static.

Meanwhile on the frame-level testing results, it can be seen that the system accuracy at the frame-level is $100 \%$ with the highest accuracy in the smoke video is $100 \%$ and the accuracy on non-smoke video is $10 \%$. Although the system can detect correctly if a frame have smoke in it, but the system is still not effective when processing non-smoke video. 


\section{CONCLUSION}

Based on the research and testing that has been done, it can be concluded that wavelet energy method can be used to detect smoke. The test results show the system accuracy on block level is $91.05 \%$ and system accuracy on frame level is $72.22 \%$. This accuracy is measured using parameters configuration of frame differencing threshold 11 , saturation threshold 0.37 , value threshold 0.64 , wavelet spatial energy range from 0.2 to 110 , and 100 frame of smoke motion frame.

The challenges for this system is when the smoke is in the frame with a background that resembles smoke color. In addition, this system often incorrectly detect smoke presence in a non-smoke videos. Based on the analysis of the testing results, it is suggested that the future development would be by using a more effective smoke motion analysis method and by adding more varied dataset video, especially videos with background that resembles smoke color.

\section{REFERENCES}

[1] K. Dimitropoulos, P. Barmpoutis and N. Grammalidis, "Smoke Detection Using Spatio-Temporal Analysis, Motion Modelling and Dynamic Texture Recognition," 2014.

[2] K. Avgerinakis, A. Briassouli and I. Kompatsiaris, "Smoke Detection Using Temporal HOGHOF Descriptors and Energy Colour Statistics from Video," International Workshop on Multi-Sensor Systems and Networks for Fire Detection and Management, 2012.

[3] F. Gomez-Rodriguez, B. C. Arrue and A. Ollero, "Smoke Monitoring and Measurement Using Image Processing," Application to Forest Fires, pp. 404-409, 2003.

[4] B. U. Toreyin, Y. Dedeoglu and A. E. Cetin, "Wavelet Based Real-Time Smoke Detection in Video," 2005.

[5] K. Dimitropoulos, P. Barmpoutis and N. Grammalidis, "Higher Order Linear Dynamical Systems for Smoke Detection in Video Surveillance Applications," 2016.

[6] B. U. Toreyin, Y. Dedeoglu and A. E. Cetin, "Contour Based Smoke Detection in Video using Wavelets," 2006.

[7] T. A. B. Wirayuda, F. Sthevanie and S. Widowati, "Fire Color Detection using Color Look Up and Histogram Analysis," 2013 International Conference of Information and Communication Technology (ICoICT), pp. 134-139, 2013.

[8] J. H. Bear, "What Is The HSV (Hue, Saturation, Value) in Color Model," 3 March 2017. [Online]. Available: https://www.thoughtco.com/what-is-hsv-in-design-1078068. [Accessed 16 May 2017].

[9] "Color," Microsoft, [Online]. Available: https://msdn.microsoft.com/ru-ru/library/dn742482(v=vs.85).aspx. [Accessed 13 July 2017].

[10] T. A. B. Wirayuda, K. A. Laksitowening, F. Sthevanie and R. Rismala, "Development Methods For Hybrid Motion Detection (Frame Difference-Automatic Threshold)," 2013 International Conference of Information and Communication Technology (ICoICT), pp. $218-222,2013$.

[11] F. Yuan, "A Fast Accumulative Motion Orientation Model Based On Integral Image For Video Smoke Detection," 2008.

[12] M. R. Islam, "Wavelets, its Application and Technique in signal and image," 2011.

[13] T. A. B. Wirayuda and I. S. Suwardi, "Fire Alarm System Based-On Video Processing," Proceedings of the 2011 International Conference on Electrical Engineering and Informatics, pp. 1-7, 2011.

[14] W. H. Li, B. Fu, L. Xiao and Y. Wang, "A Video Smoke Detection Algorithm Based on Wavelet Energy and Optical Flow Eigenvalues," 2013 
